\title{
Correlation between College Students' Pragmatic Competence and Intercultural Sensitivity
}

\author{
Jin Qian, Zhongmei Li, and Shuang Wang
}

\begin{abstract}
This study explored the intercultural sensitivity of a group of students from Dalian University of Technology, China. The purpose of the exploratory study is to discover the correlation between intercultural sensitivity and pragmatic competence. The investigation consisted of quantitative analysis of a group of 200 college students and qualitative analysis with the experiment tools of two independent questionnaires-intercultural sensitivity scale and pragmatic competence scale. After the collection of the questionnaires, the correlation analysis and regression analysis were done by SPSS17.0. In the qualitative analysis, interviews of 20 respondents were carried out with 10 students of low level of ISS and PC and 10 from high level. The result of the quantitative analysis was positive. Intercultural sensitivity and each factor of it were related to pragmatic competence. For regression analysis, interaction engagement, interaction enjoyment and interaction confidence influence pragmatic competence positively. In the qualitative analysis, the attitudes and opinions toward language learning strategy and pragmatic competence of the respondent were collected. The result is shown that high level of ISS and PC respondents were more likely to get involved into the communication activities with foreign people. The findings of both quantitative analysis and qualitative analysis proposed a number of important implications for the development of students' intercultural sensitivity and pragmatic competence.
\end{abstract}

Index Terms-Correlation analysis, intercultural sensitivity, pragmatic competence, regression analysis.

\section{INTRODUCTION}

People living in 21 st century are facing complicated problem that cannot solved in isolation, such as, environmental issues, spreading terrorism, financial crises and an imbalance in the distribution of wealth. Young people need to learn how to work collaboratively with others from different cultural backgrounds. Pragmatic competence is a measurement of one's intercultural sensitivity. Since speaker must express their attitude and feelings via words and sentences, pragmatic competence, therefore, is supposed to relate to intercultural sensitivity. In this case, the investigation of the correlation between intercultural sensitivity and pragmatic competence should be done by both quantitative analysis and qualitative analysis.

Intercultural sensitivity focused on personal emotions that are caused by different situations, people, and environment, carries a concept that an intercultural sensitive individual is

Manuscript received July 29, 2016; revised October 23, 2016. This work was supported in part by the ICHCS 2016 Organizing Committee.

Jin Qian is with the School of Foreign Languages, Dalian University of Technology, Liaoning, China (e-mail: qianjin@dlut.edu.cn).

Zhongmei Li and Shuang Wang are with Dalian Polytechnic University, Liaoning, China (e-mail: 821856333@qq.com,Wsdawn2000@163.com). able to plan and receive positive emotional responses before, during, and after intercultural interaction. It especially refers to the attitude of respect. Without knowing how to express respect to others, people experiencing cultural differences in the process of intercultural communication will feel a low degree of satisfaction. According to Gudykunst [1], a successful integration of affective and cognitive processes can help people achieve an adequate social orientation that enables them to understand their own feelings and behaviors as well as those of others. Chen [2] thought that for developing a model which could promote one's intercultural sensitivity and comprehending cultural differences, the intercultural sensitive person need the following factors: Self-Esteem; Self-Monitoring; Open-Mindedness; Empathy; Interaction Involvement; Non-Judgment.

Bhawuk and Brislin [3] developed the Intercultural Sensitivity Inventory(ICSI) to measure intercultural sensitivity by looking at people's ability to modify their behavior based on their assumption that "those who can change behaviors so that they are appropriate in other cultures are intercultural sensitive and will be successful on overseas assignments". To guide the development of the instrument, they decided to choose individualism-collectivism as the dimension for categorizing cultures. In addition, the constructs of flexibility and open-mindedness have also been considered in the measurement.

Pragmatic competence, an important component of communicative competence, refers to the ability to use language appropriately and decently in communication activities and to accomplish communicative goals. It contains the following basic characteristics: 1) comply with the rules on pragmatic language level; 2) pay attention to culture differences on the social pragmatic level; 3 ) understand the limitation of the attitude and behavior in speech acts on psychological cognitive level; 4) consider the restrictions of context on time and situation level. Pragmatic competence is not abstract, isolated or vague. It is the method of using and understanding language effectively in general communication activities.

For measuring pragmatic competence, several instruments have been evaluated from home and abroad. For example, Ziran He [4] evaluated the pragmatic competence of 79 applied linguistic teachers with a questionnaire (20 multiple choice about speech act) in Guangdong University of Foreign Studies. Gang Hong [5] used a questionnaire to compare the pragmatic competence of the English major students of two grades and obtained the result that there is no positive correlation between pragmatic competence and linguistic competence. Wenping Gan [6] 
measured the pragmatic competence of high school students and college English teachers. The questionnaire included 10 questions about greeting, thank, asking for advice and apologize, etc. Feifei Zhao [7] used a questionnaire (English-Chinese bilingual) to evaluate the pragmatic competence of college students and concluded that there is no significant difference in pragmatic competence between senior students and junior students. These questionnaires were all verified by empirical researches, yet as time goes on, the criterion of pragmatic competence has changed.

The purpose of this study was threefold. First, it aimed to present the empirical data for researching respondents' level of intercultural sensitivity and pragmatic competence. Second, it tried to reveal how the variables selected were associated with the students' level of intercultural sensitivity. The findings of this survey might provide implication for the students who want to improve their intercultural sensitivity. Third, this study also aspired to explore the differences between students of high intercultural sensitivity and students of low intercultural sensitivity in terms of their culture learning. During the process of language learning, culture learning has been evaluated as a significant factor which could foster students' interests and improve their ability of self-study. In addition, culture learning could improve students' flexibility in controlling emotion and communication. Students' culture learning experiences may contribute to a better understanding of students' development of intercultural sensitivity.

\section{Methodology}

\section{A. Participants}

The participants of this survey are 200 college students in Dalian University of Technology (DUT), China. More specifically, 113 participants are male and 87 participants are female. Their majors are varied including business management, English literature, English linguistics, chemical engineering, etc. They are between the age of 21 and 26 . These students were chosen as participants because they all have the experience of communicating with foreigners directly and indirectly.

\section{B. Instruments}

In the survey, the correlation between intercultural sensitivity (ICS) and pragmatic competence (PC) was investigated by two instruments. For intercultural sensitivity, the Intercultural Sensitivity Scale (Chen and Starosta's) was chosen. For pragmatic competence, the scale of pragmatic competence (Zhanhao Jiang) was chosen.

Based on their studies on the model of intercultural communication competence and intercultural sensitivity, Chen and Starosta develpoed Intercultural Sensitivity Scale (ISS), a generally accepted theoretical and empirical assessing tool. ISS is a questionnaire of 24-item, 5-Likert, which consists of five factors: interaction engagement, respect for cultural differences, interaction confidence, interaction enjoyment, and interaction attentiveness.

Among the lots of scales to measure English learners' pragmatic competence, the author finally selected the test created by Zhanhao Jiang from Shanghai International Studies University. The test was verified three times: First, it was evaluated by experts and professors of Shanghai International Studies University and 2 questions were removed in the final scale due to the impracticality. Then, situational question was evaluated by 31 intercultural students whose mother language is English. After the evaluation, the key of this part was given by those foreign students in the same time. Last but not least, the final evaluation was taken by the experiment of over 500 students. The validity and reliability of this questionnaire were verified finally. Through all these procedures, the questionnaire was examined highly reliable and efficient.

\section{Data Collection and Analysis}

After sending out the 2 questionnaires to the 200 participants from DUT, some instructions were given to ensure all participants get the full understanding of how to complete the questionnaire. For excluding the influence of second language, all the English words which are above the standard of CET4 are translated and labeled on the questionnaire.

All the 400 collected questionnaires (200 ISS \&200 PC) were valid, and each item on questionnaires offered valid data. Data collected were put into Statistical Package for Social Science 17.0 (SPSS17.0) and coded. Then, a series of statistical techniques were processed by several steps which will be reported in details in the following part.

\section{RESUlT AND DISCUSSION}

In this part, data acquired from the questionnaire survey are analyzed and discussed. With the result of quantitative analysis, the relationship of students' intercultural sensitivity and pragmatic competence was confirmed which also provide some angles to complete the qualitative analysis.

The statistical techniques were processed in the following steps: Firstly, descriptive statistic of five ICS factors variables were performed. Then, a correlation analysis was conducted to examine the relationship between PC and ICS. At last, a multiple regression was utilized to probe the best predictor of pragmatic competence among the five factors of ICS.

As is shown in Table I, the highest mean score (4.28) is related to the factor "Respect for Cultural Differences". Sequentially, the mean score of "Interaction Enjoyment" was 4.19, "Interaction Engagement" 3.690, "Interaction Attentiveness" 3.607 and "Interaction Confidence" 3.587. As many accomplished researches about ISS, interaction confidence is always the lowest score among other factors. Lack of confidence in the process of cross-culture communication is a serious problem for college students. Although English teaching in China has implementing for decades, the ability to output English is worse than the ability to input English. Students are shy and worry about the manner problem when they are talking with foreign people. Therefore, lots of students will escape the cross-cultural environment. On the other hand, the factor of respect for cultural differences got the highest score. Students were afraid of speaking English yet they showed high respect to 
other cultures. Other than the highest and lowest factors, students' level of Interaction Enjoyment, Interaction

Attentiveness and Interaction Engagement was relatively low.

TABLE I: DESCRIPTIVE STATISTICS OF FIVE FACTORS OF ICS

\begin{tabular}{cccc}
\hline \hline & $\mathrm{N}$ & Mean & \\
\hline Interaction Engagement & 200 & 3.690 & .4783 \\
\hline Respect for Cultural Differences & 200 & 4.280 & 3.587 \\
\hline Interaction Confidence & 200 & 3.7011 \\
\hline Interaction Enjoyment & 200 & .4749 \\
\hline Interaction Attentiveness & 200 & 3.607 \\
\hline \hline
\end{tabular}

TABLE II: CORRELATION BETWEEN PC AND FIVE FACTORS OF ICS

$\begin{array}{lllll}\begin{array}{l}\text { Interaction } \\ \text { Engagement }\end{array} & \begin{array}{l}\text { Respect for } \\ \text { Cultural Differences }\end{array} & \begin{array}{l}\text { Interaction } \\ \text { Confidence }\end{array} & \begin{array}{l}\text { Interaction } \\ \text { Enjoyment }\end{array} & \begin{array}{l}\text { Interaction } \\ \text { Attentiveness }\end{array} \\ .338^{* *} & .344^{* *} & .276^{* *} & .404^{* *} & .170^{* *} \\ .000 & .000 & .000 & .018 & .016\end{array}$

As is shown in Table II, pragmatic competence was related to all the five factors of intercultural sensitivity. The highest rate was $0.404 * *$ between pragmatic competence and interaction enjoyment. The more people get along with others the happier they will be in cross-culture communication. Hence, the high pragmatic competence clearly helps in getting more fun when people talk to their cultural counterparts. At the same time, the relationship between pragmatic competence and respect for culture differences was $0.344 * *, 0.338^{* *}$ for interaction engagement, $0.276^{* *}$ for interaction confidence and $0.170^{* *}$ for interaction attentiveness.

The highest relationship coefficient in Table III was $0.569 * *$ between interaction confidence and interaction enjoyment. The second highest correlation coefficient was $0.464 *$ between respect for culture differences and interaction engagement. The result provided the proof that accepting and respecting other cultures could increase the enjoyment in cross-culture interaction. Taking an example in our daily life, the racists always avoid talking with people who are from the minority whereas people who are open-mind with different culture would like to involve in multi-culture activity. Open-mindedness refers to the willingness of individuals to openly and appropriately explain their intention and accept other's explanations. The former involves 6 items intended to reveal how participants orient to or tolerate their counterparts' culture and opinion. Therefore, how do one respect other cultures will affect he/r to choose how much to engage in intercultural activity.

In Table IV, the significant value of interaction engagement, interaction enjoyment and interaction confidence are 0.022, 0.001 and 0.028 which are all smaller than 0.05 and significant. However, the significant value of interaction attentiveness is 0.571 which is bigger than 0.05 and not significant. The standardized correlation coefficient of interaction attentiveness is 0.038 which is quite low to predict pragmatic competence. Also, the standardized correlation coefficient of respect for cultural difference is 0.097 which could not be utilized to predict pragmatic competence.

TABLE III: CORRELATION BETWEEN FIVE FACTORS OF ICE

\begin{tabular}{lllllllll} 
F1-F2 & F2-F3 & F3-F4 & F4-F5 & F1-F3 & F1-F4 & F1-F5 & F2-F4 & \\
\hline $.464^{* *}$ & $.140^{*}$ & $.569^{* *}$ & .128 & $.221^{* *}$ & $.316^{* *}$ & $.274^{* *}$ & $.253^{* *}$ \\
\hline \hline
\end{tabular}

(F1= Interaction Engagement $\quad$ F2= Respect for Cultural Differences $\quad$ F3= Interaction Confidence F4= Interaction Enjoyment F5= Interaction Attentiveness)

To sum up, the regression coefficient of interaction engagement, interaction enjoyment and interaction confidence were $0.17,0.252$ and 0.15 which were all positive. It means that those three factors have positive impact on pragmatic competence. That is to say, the improvement of pragmatic competence will enhance one's intercultural sensitivity by improving interaction engagement, interaction enjoyment and interaction confidence. 
TABLE IV: MUlTiPLE RegReSSION BETWEen PC AND Five FACTORS OF ISS

\begin{tabular}{|c|c|c|c|c|c|}
\hline & \multicolumn{2}{|c|}{ Unstandardized Coefficients } & \multirow{2}{*}{ Standardized coefficients } & \multirow{2}{*}{$\mathrm{t}$} & \multirow{2}{*}{ Sig. } \\
\hline & $\mathrm{B}$ & Std. Error & & & \\
\hline (Constant) & 34.65 & 5.79 & & 5.985 & 0 \\
\hline Interaction Engagement & 0.451 & 0.196 & 0.17 & 2.304 & 0.022 \\
\hline Respect for culture difference & 0.288 & 0.243 & 0.097 & 1.186 & 0.237 \\
\hline Interaction Enjoyment & 1.168 & 0.361 & 0.252 & 3.231 & 0.001 \\
\hline Interaction confidence & 0.396 & 0.178 & 0.15 & 2.219 & 0.028 \\
\hline Interaction Attentiveness & 0.148 & 0.261 & 0.038 & 0.568 & 0.571 \\
\hline
\end{tabular}

Interaction Enjoyment, according to the unstandardized coefficient, is the best predictor of pragmatic competence. In practice, to enhance students' interaction enjoyment could help them improving pragmatic competence, and vice versa. Sequentially, interaction engagement and interaction confidence influence pragmatic competence positively, too. It is not hard to find out that getting involved in cross-cultural activity is significant for pragmatic competence. In addition, interaction confidence and interaction enjoyment were important factors to contribute the intercultural activity. All in all, the improvement of pragmatic competence might not be got by learning from the teaching materials in the classroom, yet it is attainable by engaging in the practice cross-cultural activity.

After the quantitative analysis, a quantitative analysis was necessary to do. An interview was held with 20 participants. Those participants were separated in two groups-high score group and low score group. The questions were supposed to collect the attitudes and opinions from high scored respondents and low scored respondents.

Firstly, the proactive in communication was measured by the question: "When you are involved in an interaction, which side should start the conversation? What kind of topic is selected regularly?" The answers from high score group and low score group were different as the former tend to attend the communication actively and the later were often not confident enough to start the conversation.

Secondly, about the opinions on pragmatic competence, the question was proposed as: "Is language knowledge or the ability of using language appropriately more important when you use a language?". The most high score group students believe that pragmatic competence plays an important role in language learning. Low score group, on the other hand, tend to choose language knowledge over pragmatic competence.

Thirdly, the strategies of high score group and low score group were compared. There were four main strategies: First, reading English literature; Second, communicating with foreign teachers or people; Third, using the Internet to Learn language; Fourth, intercultural Experiences.

\section{CONCLUSION}

According to the main findings of the survey, there is the correlation between ICS and PC, and the improvement of ICS and PC could be bilateral. Therefore, implications and suggestions were given for English learners and teachers.
The highest priority of improving ICS is enriching personal cultural experiences. The cultural experience consists of any encounter between learners and another way of life, be it first-hand through direct involvement with people of the other culture or indirectly through learning materials in the language classroom. Context, in communication activities, is very significant. If speakers could understand the context correctly, the possibility of successfully complete the conversation will be highly increased. Following are some suggested strategies for English learners: Inspiring personal cross-culture experiences has to be implicated as soon as possible; Taking part in cross-culture activities and communicating with foreign teachers is the fastest way; Making great use of the internet as a resource bank is also significant in language learning; And reading foreign literature is important, too.

The implications of the survey for language teaching and improving intercultural sensitivity and pragmatic competence are as followed: First, focusing on creating active teaching methods to improve students' pragmatic competence is needed instead of teaching language manner or vocabulary. The topics should be updated frequently. Critical incidents, cultural assimilators, cultural simulations, field experiences, values clarification and experiential activities are all great materials in the class. Second, instead of waiting for cross-culture activities, teacher could organize intercultural learning activities. Changing the class into round table party and inviting foreign students and teachers to share their experiences would be fascinating to attract students' attention. Third, teachers should also develop some ways to assess students' pragmatic competence and intercultural sensitivity. The evaluation of students' final score could be done by measuring both pragmatic competence and intercultural sensitivity as well. The final exam might be a short interview instead of paper exam. By this way, the students would transfer their focus from remembering knowledge to thinking about how to express in English.

To the researchers who expect to propose more valuable findings on pragmatic competence and intercultural sensitivity, there are some aspects. First, the research on diachronic study of students' intercultural sensitivity and pragmatic competence is strongly needed in pedagogy revolution. Second, more factors that influence intercultural sensitivity were needed to be identified in the future. The more factors of influence are found, the better the 
intercultural sensitivity will improve. Third, to develop a culture learning strategy inventory is significant. Once students could put all energy in learning culture, the understanding of the language will be harvested abundantly. Also, there will be a scientific measurement of students to form their own systematic learning of another language. Therefore, future study should be expected to the development of an assessment tool to evaluate students' culture learning strategy.

\section{REFERENCES}

[1] W. B. Gudykunst, "Toward a theory of effective interpersonal and intergroup communication: An anxiety/uncertainty management (AUM) perspective," Intercultural Communication Competence, 1993 , pp. 33-71.

[2] G. M. Chen and W. J. Starosta, "A review of the concept of intercultural sensitivity," Human Communication, vol. 1, pp. 12-16, Janu.1997.

[3] D. P. S. Bhawuk and R. Brislin, "The measurement of intercultura sensitivity using the concepts of individualism and collectivism,' International Journal of Intercultural Relations, vol.16, pp. 413-436, 1992.

[4] Z. R. He, "Hedges and verbal communication," Journal of Foreign Languages, vol. 5, pp. 29-33, 1985.

[5] G. Hong, "Survey on English pragmatic competence and its implications for foreign language teaching," Foreign Language Teaching and Research, vol. 4, pp. 56-60, 1991.

[6] W. P. Gan, "Investigation and analysis of the Chinese college students' English pragmatic competence," Journal of Xi'an Foreign Languages University, vol. 1, pp. 73-76, September 2001.

[7] F. F. Zhao, Pragmatic Competence and College English Teaching, 2006.

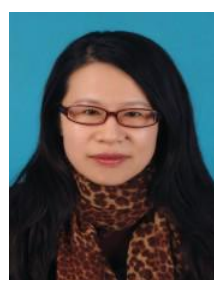

Jin Qian was born in Liaoning province, China on Oct. 12, 1968. She received her master of education from Sydney University, Australia in 2002, majoring in educational psychology.

She has been English teacher and researcher in School of Foreign Languages, Dalian University of Technology (DUT), China since 1990. During the period, she pursued her master program in Sydney University in 2001 and did her doctorial research in the field of intercultural communication in the Faculty of Education, Durham University, U.K. in 2012. Currently, she is working as associate professor and supervisor of master students in School of Foreign Language, DUT with research interests in applied linguistics and cross-cultural studies. Her paper Fostering Students' Self-Management Ability during their Study: An Empirical Study on the Application of Portfolios in an Autonomous College English Class was published by Cambridge Scholars Publishing in 2014.
Ms. Qian is a member of Centre of Tertiary Education Research, DUT. In 2011, Ms. Qian with her colleagues completed a research project funded by Education ministry of China entitled The Practice of Educational Reform on ESP in Science and Technology University Context and Research on the Textbooks. She received a University Excellence in Teaching Award in 2009, 2013 and 2015 respectively.

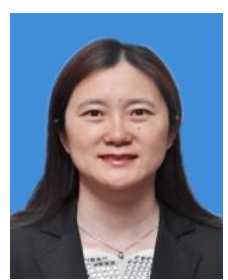

Zhongmei Li was born in Dalian, Liaoning, China on Feb. 14th, 1974. She received her B.A. in English from Dalian University of Foreign Languages in 1999 and M.A. in foreign linguistics and applied linguistics from Dalian University of technology in 2009.

She was a translator from 1999 to 2002 . And she has been an English teacher in Dalian Polytechnic University since 2002. Her paper titled The Effects of Teacher Role in Web-Based English Listening Autonomous Learning was published by Cambridge Scholars Publishing in 2014. She translated the book named Why Won't My Teenager Talk To Me? and got it published in Shanghai by East China Normal University Press in 2016. Her research interests include EFL teaching and learning and translating.

Ms Li is a member of the Team of College English Reform in DLPU. She received a University Excellence in Teaching Award in 2004 and was honored as the Advanced Individual in Education in 2005. Now she is the dean of the Graduate English Teaching Office of the university.

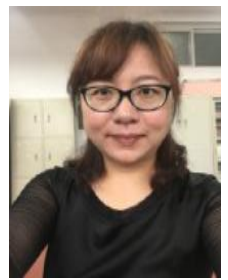

Shuang Wang was born in Liaoning province, China on July 4th, 1979 and got her master's degree in English language and literature at Jilin University, Changchun, Jilin Province, China, in 2004. Her major field of study is teaching English as a second foreign language.

She works in Dalian University of Technology, Dalian, China as lecture. She has published the following articles: 1). "Cultivating cross-cultural awareness in teaching world literature to non-English majors," Time Education, 2015; 2). "Teaching English literature to non-English majors and close reading," College Education, 2015. 